\title{
Extraction of metals from municipal solid waste incinerator fly ash by hydrothermal process
}

\author{
Fu-Shen Zhang a,b,*, Hideaki Itoh ${ }^{\mathrm{b}}$ \\ ${ }^{a}$ Research Center for Eco-Environmental Sciences, Chinese Academy of Sciences, 18, Shuangqing Road, Beijing 100085, China \\ ${ }^{\mathrm{b}}$ Division of Environmental Research, EcoTopia Science Institute, Nagoya University, Furo-cho, Chikusa-ku, Nagoya 464-8603, Japan
}

Received 26 May 2005; received in revised form 2 November 2005; accepted 22 December 2005

Available online 6 March 2006

\begin{abstract}
This work examined the extraction properties of metallic elements from municipal incinerator fly ash under hydrothermal conditions. The ash was firstly pre-washed by distilled water, then subjected to hydrothermal treatments. The pre-washing process was effective for $\mathrm{Na}$, K, Ca extraction with extraction percentages of $67 \%, 76 \%$ and $48 \%$, respectively. The optimum contact time was 30 min for the pre-washing process. Five types of acids were tested for the extraction experiments and hydrochloric acid was found to be most effective for metal extraction from the ash. Compared to room condition, hydrothermal treatment accelerated the dissolution of the ash, thus promoted the reaction of acid with hazardous metals such as $\mathrm{Cr}, \mathrm{Cd}, \mathrm{Pb}$, and furthermore, the consumption speed of acid was slowed down under hydrothermal condition. The acid simultaneously reacted with all the metal in the ash under hydrothermal condition but preferentially reacted with $\mathrm{Ca}$ at room condition. The optimum hydrothermal treatment temperature, time and liquid/solid ratio were $150^{\circ} \mathrm{C}, 5 \mathrm{~h}$ and $10: 1(\mathrm{ml}: \mathrm{g})$, respectively.
\end{abstract}

(C) 2006 Elsevier B.V. All rights reserved.

Keywords: Hydrothermal extraction; MSW fly ash; Heavy metal; Crystallization

\section{Introduction}

Fly ash discharged from municipal solid waste (MSW) incineration plant has been classified as "hazardous waste requiring special control" in many developed countries for several years. In Japan, regulated by 1992 legislation [1], the fly ash is generally subject to treatment by any of the four ways, i.e. melting treatment, chemical stabilization, cement solidification, or extraction. Converting the ash into slag by melting process has been improved in recent years since the melted slag has the potential to be used as construction materials such as aggregates and ceramic linings [2,3]. The only shortcoming of this process is that it is much more costly compared with other methods, which makes it difficult for exact application. In-situ stabilization/solidification of heavy metals inside the fly ash using chelate agents or mixing the ash with Portland cement, on the other hand, is also practicing alternative nowadays for the relatively low treatment

\footnotetext{
* Corresponding author at: Research Center for Eco-Environmental Sciences, Chinese Academy of Sciences, 18, Shuangqing Road, Beijing 100085, China. Tel.: +86106284 9515; fax: +861062849515.

E-mail address: fszhang @ rcees.ac.cn (F.-S. Zhang).
}

cost and ease of application. However, these processes present some drawbacks, namely slow releasing of heavy metals from the treated ash in a wet environment, which makes it still be hazardous for the environment $[4,5]$. Moreover, solidification with Portland cement could considerably increase the volume and weight of the residue, since the solidification operation usually adds $15-30 \mathrm{wt} . \%$ of cement and $1-3 \mathrm{wt} . \%$ of chemical reagent such as carboxylic, thiol or carbamate functional groups with the fly ash [4]. Comparably, extraction of heavy metals from the fly ash is an environmentally preferable method for the ash treatment. This process is actually a hydrometallurgical process as most of the metals may dissolve in the acidic solution.

The recovery of base metals such as $\mathrm{Cu}, \mathrm{Ni}, \mathrm{Co}, \mathrm{Zn}$ and $\mathrm{Pb}$ from waste ashes provides an opportunity to convert the hazardous waste to innocuous material while at the same time extracting valuable pay-metals. To date, various hydrometallurgical methods using lixiviation reagents for metal extraction from waste ashes have been examined [6-8]. Among the reagents, mineral acids such as $\mathrm{HCl}, \mathrm{HNO}_{3}, \mathrm{H}_{2} \mathrm{SO}_{4}$, and alkaline solutions such as $\mathrm{NaOH}$ and aqueous $\mathrm{NH}_{3}$, are frequently employed. Hydrochloric acid and nitric acid have the advantages of extracting almost all metallic elements, and sulfuric acid could dissolve many of the metals but leave $\mathrm{Ca}$ and $\mathrm{Pb}$ 
in the residue, while alkaline solutions have the advantages of selective extraction of amphoteric metals such as $\mathrm{Zn}$ and $\mathrm{Pb}$ and leave other metals in the solid residue. Nevertheless, a large amount of acids or alkaline solutions are generally needed for these processes, and furthermore, the resulting solutions are usually extremely acidic or alkaline with only low concentration of metals in the resulting leachate, which are difficult for recovery. Hence, these processes require high-level wastewater control, and are not suitable for ash disposal plants without wastewater treatment equipments.

Hydrothermal process is a functional way to active reactions whose major mechanism is via dissolution. In recent years, this technique has been applied to waste ash treatment so as to recycle the waste material. Many researchers have employed coal fly ash as a precursor material trying to convert the ash to zeolitelike materials in an alkaline condition. Thus far, many types of zeolite such as phillipsite, analcime, zeolite $\mathrm{P}$, gismondine, and gmelinite have been successfully synthesized using fly ashes [9-11]. Recent reports also indicated that hydrothermal process could significantly increase fly ash pozzolanic reaction $[12,13]$. The resulting compounds can be used for immobilizing toxic wastes, and also have the potential to be used as the precursors of new kind of low-energy cements called fly ash belite cements. Furthermore, it has reported that hydrothermal treatment of MSW incinerator fly ash with water or alkaline solution could decompose dioxins such as PCDDs and PCDFs through dechlorination, especially at high temperature [14-16].

Many outstanding advantages have been demonstrated in waste ash recycle by hydrothermal treatment. To the knowledge of the authors, however, the leaching properties of heavy metals from fly ash under hydrothermal condition are less reported in the literature. In the present study, hydrothermal treatments on MSW incinerator fly ash were conducted so as to understand the extraction behaviors of metallic elements from the ash during hydrothermal process. The aim was to extract more metals using less acid. The optimum leaching conditions were established, and the crystalline and morphological properties of the residue were clarified.

\section{Experimental}

Fly ash was obtained from a MSW incineration plant in Nagoya, Japan. The plant has two $24 \mathrm{~h}$ running large-scale PLC based incinerators, and the furnace of each incinerator is design to dispose more than 5-tonne refuse per hour. The furnace room temperature is sustained within $850-1000{ }^{\circ} \mathrm{C}$. The fly ash was captured by a bag-filter and was removed twice every day. The fly ash typically contains metallic elements such as $\mathrm{Na} 2.91 \%, \mathrm{Mg} 1.08 \%, \mathrm{Al} 2.83 \%, \mathrm{~K} 4.11 \%$, Ca $22.5 \%, \mathrm{Cr}$ $0.18 \mathrm{~g} \mathrm{~kg}^{-1}$, Mn $0.97 \mathrm{~g} \mathrm{~kg}^{-1}$, Fe $7.63 \mathrm{~g} \mathrm{~kg}^{-1}, \mathrm{Cu} 0.90 \mathrm{~g} \mathrm{~kg}^{-1}$, $\mathrm{Zn} 17.3 \mathrm{~g} \mathrm{~kg}^{-1}, \mathrm{Cd} 0.14 \mathrm{~g} \mathrm{~kg}^{-1}, \mathrm{~Pb} 1.00 \mathrm{~g} \mathrm{~kg}^{-1}$ with variation limits around $0.03-1.23 \%$, and non-metallic elements such as $\mathrm{C}$ $7.0 \%, \mathrm{Si} 4.0 \%, \mathrm{P} 0.28 \%, \mathrm{~S} 0.84 \%, \mathrm{Cl} 28.3 \%$ with variation limits around $0.08-8.17 \%$. Carbon content in the ash was determined using a CHN corder (Yanako, MT-6), and the other non-metallic elements were exmined using a scanning electron microscope (SEM, JSM-6330F) coupled with an energy-dispersive X-ray spectrometer (EDS, JED-2140). The details of the fly ash were presented in a previous report [17].

The fly ash was firstly vacuum dried at $105^{\circ} \mathrm{C}$ for $24 \mathrm{~h}$. Then a portion of the ash was pre-washed by distilled water. In the pre-washing process, a liquid/solid ratio of 20:1 (ml:g) was performed. The vibration time varied from $5 \mathrm{~min}$ to $20 \mathrm{~h}$, and the temperature was approximately $20^{\circ} \mathrm{C}$. After vacuum filtration, metallic elements in the leachate were determined using inductively coupled plasma atomic emission spectroscopy (ICP-AES, Perkin-Elmer).

After separation, the pre-washed residue was vacuum dried at $105^{\circ} \mathrm{C}$ for $24 \mathrm{~h}$ and subjected to hydrothermal treatments. A series of autoclaves were employed for the hydrothermal experiments. Each autoclave consists of a $50 \mathrm{ml}$ Teflon interior and a stainless exterior. The pressures inside changes along with the temperature change, which were around 1.2-2.0 MPa. Hydrochloric acid, nitric acid, sulfuric acid, oxalic acid and citric acid were examined to compare their leaching effects. The treatment time varied from 1 to $70 \mathrm{~h}$, and the temperatures varied from 100 to $200^{\circ} \mathrm{C}$. Liquid/ solid ratios of 3:1, 5:1, 10:1 and 20:1 (ml:g) were performed. After hydrothermal treatment, the autoclaves were immediately cooled using an electronic fan. Upon cooling, the supernatant solution was filtrated using a vacuum filter. Metallic elements in the leachate were determined by ICPAES, and the $\mathrm{pH}$ of the solution was measured using a HORIBA D-21 pH meter. For comparison, parallel experiments were also conducted at room conditions.

The crystalline properties of the residue and the original ash were examined by a RIGAKU X-ray diffractometer (XRD, Rint 2000) at $50 \mathrm{kV}$ and $100 \mathrm{~mA}$ using $\mathrm{Cu} \mathrm{K} \alpha$ radiation $(\lambda=1.5418 \AA)$, and the surface morphology was examined by SEM. A high performance liquid chromatograph (HPLC, SHIMAZU) was employed for $\mathrm{Cl}^{-}, \mathrm{SO}_{4}{ }^{2-}$ and $\mathrm{NO}_{3}{ }^{-}$determination. Oxalic anion in the filtrate was precipitated with calcium chloride and determined by $\mathrm{KMnO}_{4}$ titration, while citric anion was titrated with sodium methanolate in a 3:1 methanol/dimethylformamide mixture.

The quality and precision of metallic element analysis for the fly ash and other samples were controlled using four reference materials, i.e. coal ash (ZUK-1) from Institute of Geochemistry, Irkutsk (Russia), bone ash (NIST 1400) from National Institute of Standards and Technology (USA), and two sewage sludge (nos. 101 and 102) from National Institute of AgroEnvironmental Science, Ministry of Agriculture, Forestry and Fisheries (Japan). The recoveries for the elements were: $\mathrm{Na}$ (94-97\%), Mg (93-96\%), Al (95-103\%), K (101-106\%), Ca (95-99\%), Ti (102-110\%), V (97-101\%), Cr (106-115\%), Mn (91-98\%), Fe (102-108\%), Co (95-99\%), Ni (93-100\%), Cu (98-106\%), Zn (103-110\%), As (99-100\%), Sr (100-102\%), Cd (101-103\%), Ba (96-99\%), Pb (99-101\%), respectively.

\section{Results and discussion}

\subsection{Pre-washing effects}

In the metal extraction processes, the most economic approach is simply washing the fly ash with water to separate 


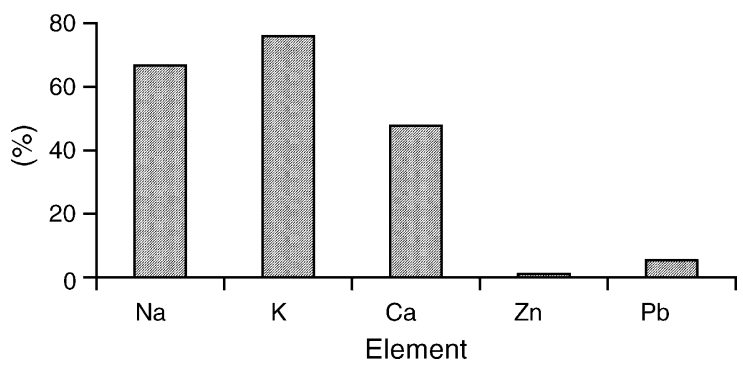

Fig. 1. Leaching percentage of metals by distilled water in the pre-treatment process. Liquid $/ \mathrm{solid}=20 \mathrm{ml} / \mathrm{g}$, contact time $=30 \mathrm{~min}$, temperature $=20^{\circ} \mathrm{C}$.

insoluble minerals from water-soluble compound. In this way, a large amount of liquor can be saved in the subsequent acid washing process. Fig. 1 illustrates that a large amount of $\mathrm{Na}, \mathrm{K}, \mathrm{Ca}$ were washed out from the ash during the pre-washing treatment, with leaching percentages of $67 \%, 76 \%$ and $48 \%$, respectively, Furthermore, approximate $1 \% \mathrm{Zn}$ and $5 \% \mathrm{~Pb}$ were also leached out into the leachate. Though in low concentrations, $32 \% \mathrm{Sr}$ and $38 \% \mathrm{Ba}$ were also leached out into the solution, which were not shown in Fig. 1. XRD diffraction pattern of the fly ash indicates that some of the $\mathrm{Na}$ and $\mathrm{K}$ in the ash are in the crystal forms of $\mathrm{NaCl}$ and $\mathrm{KCl}$, which are easy to dissolve into water, but no crystalline peaks for $\mathrm{Ca}$ are found, implying that $\mathrm{Ca}$ in the ash exists in its amorphous form (Fig. 2). Calcium is mainly introduced into the ash from exterior since a solution suspension of lime is used as the neutralizer for treating the flue acid gas from the incinerator. Thereby, $\mathrm{Ca}$ in the ash is supposed to be in the forms of $\mathrm{CaCl}_{2}, \mathrm{Ca}(\mathrm{OH})_{2}, \mathrm{CaS}, \mathrm{Ca}(\mathrm{HS})_{2}, \mathrm{CaSO}_{4}$, etc.
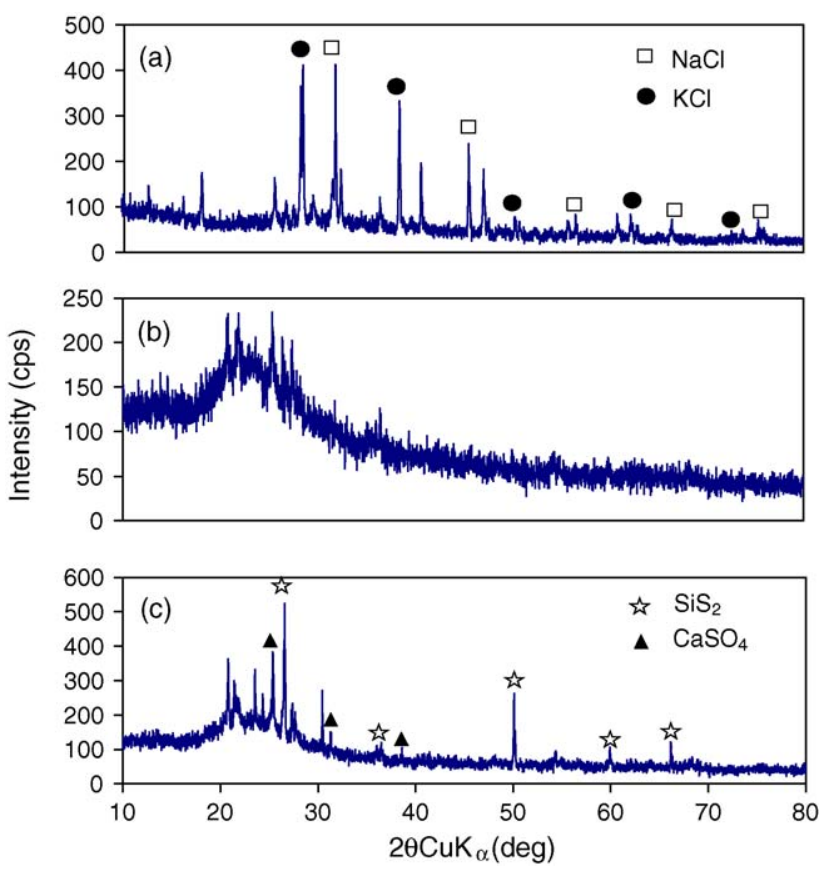

Fig. 2. XRD patterns of untreated and hydrothermal treated IFA. (a) Original IFA; (b) $5 \mathrm{~h}$ treated IFA; (c) $40 \mathrm{~h}$ treated IFA. Hydrothermal conditions: liquid $/$ solid $=10$, temperature $=150^{\circ} \mathrm{C}$.
Table 1

Leaching of elements from the fly ash by distilled water in the pre-treatment process $\left(\mathrm{mg}^{-1}\right)$

\begin{tabular}{lccccccc}
\hline & $5 \mathrm{~min}$ & $10 \mathrm{~min}$ & $30 \mathrm{~min}$ & $1 \mathrm{~h}$ & $5 \mathrm{~h}$ & $10 \mathrm{~h}$ & $20 \mathrm{~h}$ \\
\hline $\mathrm{Na}$ & 832 & 842 & 889 & 894 & 832 & 837 & 837 \\
$\mathrm{Mg}$ & 0.03 & 0.01 & 2.91 & 0.14 & 0.07 & 0.08 & 0.01 \\
$\mathrm{Al}$ & 0.21 & 0.24 & 0.54 & 0.75 & 0.33 & 0.14 & 0.14 \\
$\mathrm{~K}$ & 1498 & 1492 & 1544 & 1487 & 1425 & 1555 & 1482 \\
$\mathrm{Ca}$ & 5512 & 5512 & 5668 & 5408 & 5106 & 5408 & 5356 \\
$\mathrm{Cu}$ & 1.55 & 1.08 & 0.85 & 0.65 & 0.08 & 0.06 & 0.32 \\
$\mathrm{Zn}$ & 20.2 & 9.72 & 8.62 & 6.64 & 5.23 & 6.53 & 5.40 \\
$\mathrm{As}$ & 4.14 & 0.31 & 0.08 & 0.04 & 0.07 & 0.08 & 0.07 \\
$\mathrm{Sr}$ & 5.77 & 4.33 & 4.49 & 4.40 & 4.24 & 4.79 & 4.70 \\
$\mathrm{Ba}$ & 1.26 & 1.33 & 1.39 & 1.38 & 1.26 & 1.46 & 1.41 \\
$\mathrm{~Pb}$ & 3.48 & 2.88 & 2.56 & 2.19 & 1.47 & 1.72 & 1.87 \\
\hline
\end{tabular}

Liquid $/ \mathrm{solid}=20 \mathrm{ml} / \mathrm{g}$.

The extraction of metallic elements, such as $\mathrm{Na}, \mathrm{K}, \mathrm{Ca}$, from the ash rapidly reached maximum value, and longer time contact of the ash with water could only reduce the extraction amount of some of the hazardous heavy metals (Table 1). For example, the extraction amount of $\mathrm{Zn}$ and $\mathrm{Pb}$ at 5 min was 20.2 and $3.48 \mathrm{mg} \mathrm{l}^{-1}$, compared to the amount of 5.40 and $1.87 \mathrm{mg} \mathrm{l}^{-1}$ at $20 \mathrm{~h}$. During the pre-washing process, the $\mathrm{pH}$ value of the suspension rapidly changed from around 5.5 to around 12.5 within $5 \mathrm{~min}$, and was almost changeless during the $20 \mathrm{~h}$ vibration. Hence, it is supposed that part of the previously extracted metals precipitated in the alkaline solution along with the contact time.

Moreover, it is noted from Table 1 that the extraction amount of $\mathrm{As}$ and $\mathrm{Pb}$ at $5 \mathrm{~min}$ was 4.14 and $3.48 \mathrm{mg} \mathrm{l}^{-1}$, respectively, which surpassed the standard value of $0.1 \mathrm{mg} \mathrm{l}^{-1}$ for wastewater treatment regulated by many developed countries including Japan [18]. However, the concentration of As at 30 min reduced to $0.08 \mathrm{mg} \mathrm{l}^{-1}$ along with the contact time, which could attribute to the formation of $\mathrm{Ca}\left(\mathrm{HAsO}_{3}\right)_{2} \cdot n \mathrm{H}_{2} \mathrm{O}$ and $\mathrm{Ca}_{3}\left(\mathrm{AsO}_{4}\right)_{2} \cdot n \mathrm{H}_{2} \mathrm{O}$ [18]. Accordingly, it is suggested that the optimum contact time is $30 \mathrm{~min}$ for the pre-washing process. In this case, the washing solution could be simply drained off after $\mathrm{Pb}$ disposal.

\subsection{Acid selection}

In this section, extraction experiments at room condition and under hydrothermal treatment were simultaneously carried out. Similar treads for the five types of tested acids were obtained for the two conditions, thus only the results of hydrothermal treatment were presented in Table 2.

Organic acids are known to selectively extract metals from various materials. In this study, Oxalic acid and citric acid were tested for the extraction experiments. Generally, metal extraction effects from fly ash by organic acids are lower than those of mineral acids. The two types of organic acids are generally effective for $\mathrm{Na}, \mathrm{Mg}, \mathrm{K}, \mathrm{Mn}, \mathrm{Sr}$ extraction. Oxalic acid has the least extraction effect for many of the heavy metals compared with other acids, especially for $\mathrm{Ca}, \mathrm{Ti}, \mathrm{Zn}, \mathrm{Cd}, \mathrm{Pb}$ extraction. Additionally, considering the high cost of organic acids comparing with mineral acids, we do not recommend organic acids as metal leaching reagent for fly ashes. On the other hand, it was 
Table 2

Comparison of element leaching effects by different acids under hydrothermal treatment $(\%)$

\begin{tabular}{|c|c|c|c|c|c|}
\hline & $\mathrm{HCl}$ & $\mathrm{H}_{2} \mathrm{SO}_{4}$ & $\mathrm{HNO}_{3}$ & Oxalic acid & Citric acid \\
\hline Final $\mathrm{pH}$ & 2.63 & 2.41 & 2.63 & 3.52 & 4.61 \\
\hline $\mathrm{Na}$ & 62.1 & 23.2 & 54.9 & 78.9 & 62.0 \\
\hline $\mathrm{Mg}$ & 50.0 & 48.1 & 49.7 & 50.9 & 29.9 \\
\hline $\mathrm{Al}$ & 28.9 & 28.8 & 28.5 & 7.79 & 6.83 \\
\hline K & 56.8 & 52.1 & 54.3 & 49.2 & 52.5 \\
\hline $\mathrm{Ca}$ & 77.7 & 7.85 & 76.5 & 1.84 & 48.8 \\
\hline $\mathrm{Ti}$ & 6.80 & 8.18 & 6.70 & 1.03 & 3.80 \\
\hline V & 13.1 & 43.6 & 2.94 & 8.48 & 6.69 \\
\hline $\mathrm{Cr}$ & 13.6 & 19.3 & 7.59 & 16.6 & 8.17 \\
\hline $\mathrm{Mn}$ & 35.6 & 38.1 & 35.3 & 36.6 & 32.4 \\
\hline $\mathrm{Fe}$ & 10.1 & 11.1 & 10.1 & 6.85 & 8.63 \\
\hline $\mathrm{Co}$ & 13.0 & 11.2 & 12.9 & 5.90 & 6.12 \\
\hline $\mathrm{Ni}$ & 18.2 & 10.3 & 13.5 & 3.51 & 2.87 \\
\hline $\mathrm{Cu}$ & 25.8 & 25.5 & 24.2 & 0.48 & 0.96 \\
\hline $\mathrm{Zn}$ & 47.8 & 47.5 & 47.6 & 9.23 & 41.9 \\
\hline As & 36.5 & 45.8 & 35.7 & 63.0 & 7.58 \\
\hline $\mathrm{Sr}$ & 89.6 & 83.2 & 88.5 & 56.9 & 36.1 \\
\hline $\mathrm{Cd}$ & 99.8 & 97.3 & 99.5 & 16.6 & 34.6 \\
\hline $\mathrm{Ba}$ & 10.5 & 6.54 & 9.24 & 6.50 & 3.11 \\
\hline $\mathrm{Pb}$ & 58.6 & 2.82 & 58.6 & 12.2 & 44.4 \\
\hline
\end{tabular}

Acid concentration $=1 \mathrm{M}$, liquid $/$ solid $=5 \mathrm{ml} / \mathrm{g}$, temperature $=150^{\circ} \mathrm{C}$, treatment time $=5$.

found that not all the organic onions remain in the solution after the extraction process, e.g. the concentrations of oxalic and citric onions in the filtrate were 0.75 and $0.89 \mathrm{moll}^{-1}$, respectively.

Comparatively, mineral acids are much more effective for metal extraction from the ash. $\mathrm{H}_{2} \mathrm{SO}_{4}$ is not efficient for $\mathrm{Ca}$ and $\mathrm{Pb}$ extraction because of the formation of $\mathrm{CaSO}_{4}$ and $\mathrm{PbSO}_{4}$, e.g. the extraction percentages of $\mathrm{Ca}$ and $\mathrm{Pb}$ by $\mathrm{H}_{2} \mathrm{SO}_{4}$ were $7.85 \%$ and $2.82 \%$, compared to those of around $77 \%$ and $58 \%$ by $\mathrm{HCl}$ and $\mathrm{HNO}_{3}$, respectively. Similar extraction effects for $\mathrm{HCl}$ and $\mathrm{HNO}_{3}$ were found with the exception of the lower extraction percentages for $\mathrm{V}, \mathrm{Cr}$ and $\mathrm{Ni}$ by $\mathrm{HNO}_{3}$. In addition, it is understood that hydrochloric acid is easy to handle at low cost, hence we recommend this acid as extraction reagent for fly ash. After the extraction process, no significant change of $\mathrm{Cl}^{-}$and $\mathrm{NO}_{3}{ }^{-}$concentrations were found, but the concentration of $\mathrm{SO}_{4}{ }^{2-}$ in the filtrate reduced to $0.72 \mathrm{moll}^{-1}$, indicating that part of $\mathrm{SO}_{4}{ }^{2-}$ ion was transferred into the residue as precipitates such as $\mathrm{CaSO}_{4}$ and $\mathrm{BaSO}_{4}$. Furthermore, distilled water was also tested for metal extraction under hydrothermal treatment, but no significant amount of elements was extracted.

\subsection{Comparison of metal extraction effects under hydrothermal treatment and at room condition}

Metal extraction effects under hydrothermal and room conditions at liquid/solid ratios of 3:1,5:1,10:1 (ml:g) were examined. Only the results of 5:1 were illustrated in Fig. 3 since similar trends for the three cases were found. Hydrothermal treatment is much more effective for metal extraction compared to room condition. For example, at room condition, the extraction of $\mathrm{Al}, \mathrm{V}$, $\mathrm{Cr}, \mathrm{Fe}, \mathrm{Cu}$ and As could not be detected, but around $10-35 \%$ of

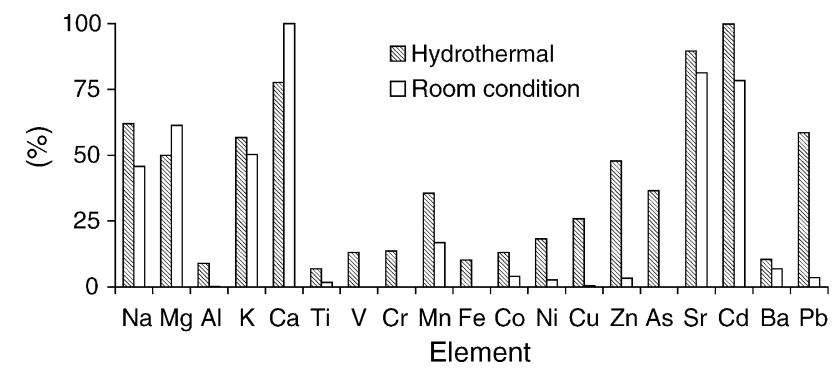

Fig. 3. Element leaching percentages by $1 \mathrm{M} \mathrm{HCl}$ solution under hydrothermal treatment and room condition. Hydrothermal conditions: liquid/solid $=5 \mathrm{ml} / \mathrm{g}$, temperature $=150^{\circ} \mathrm{C}$, treatment time $=5 \mathrm{~h}$; room conditions: liquid $/$ solid $=5$, temperature $=20^{\circ} \mathrm{C}$, treatment time $=5 \mathrm{~h}$.

these elements could be leached out under hydrothermal condition. As one of the environmentally concerned hazardous metals, approximately $60 \%$ of $\mathrm{Pb}$ could be leached out compared to $3 \%$ at room condition. One interesting result from Fig. 3 is that almost $100 \%$ of $\mathrm{Ca}$ could be leached out at room condition, while $77 \%$ of $\mathrm{Ca}$ was leached out under hydrothermal treatment. This could attribute to the special forms of the acid and the mechanisms of hydrothermal process. It has been reported that hydrochloric acid is almost completely ionized at room temperature, but aqueous molecular $\mathrm{HCl}$ dominates at high temperature such as above $250^{\circ} \mathrm{C}$ [19]. Accordingly, it is supposed the hydrochloric acid was partly ionized under the hydrothermal conditions in the present study. This state could restrain the consumption of the acid by $\mathrm{Ca}$. On the other hand, it is understood that one of the main mechanisms of hydrothermal process is via dissolution, i.e. accelerate the dissolution of the ash into the liquor. Thus, it is concluded that hydrochloric acid preferentially reacts with $\mathrm{Ca}$ at room condition, but simultaneously react with all the metal in the ash under hydrothermal condition. Hydrothermal treatment promoted the reaction of acid with hazardous metals such as $\mathrm{Cr}, \mathrm{Cd}, \mathrm{Pb}$, and furthermore, slowed down the consumption speed of the acid. This was well explained by the $\mathrm{pH}$ changes during the extraction processes. Fig. 4 depicts the $\mathrm{pH}$ changes under hydrothermal treatment and at room condition. The $\mathrm{pH}$ of the leachate increased from $0.17 \mathrm{pH}$ of the original liquor) to around 5 within $30 \mathrm{~min}$ at room condition,

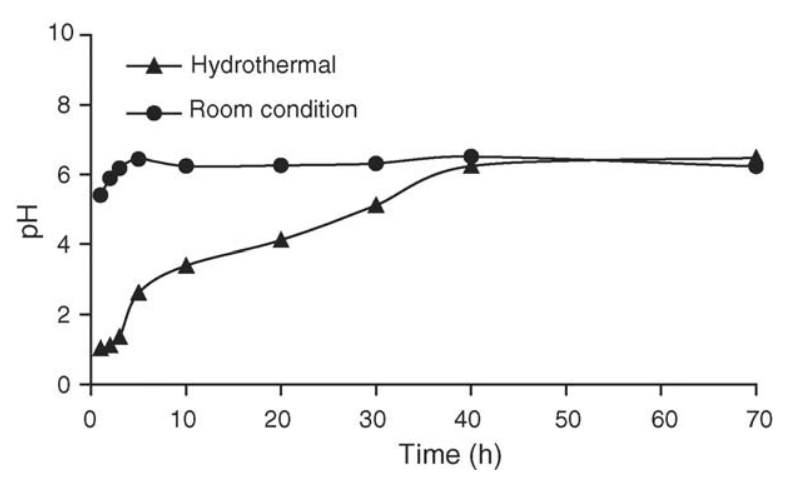

Fig. 4. $\mathrm{pH}$ changes during metal leaching process by $1 \mathrm{M} \mathrm{HCl}$ solution. Liquid $/ \mathrm{solid}=5 \mathrm{ml} / \mathrm{g}$, hydrothermal temperature $=150^{\circ} \mathrm{C}$, room temperature $=20^{\circ} \mathrm{C}$. 
Table 3

Element leaching percentages by $1 \mathrm{M} \mathrm{HCl}$ solution along with hydrothermal treatment time (\%)

\begin{tabular}{|c|c|c|c|c|c|c|c|c|c|c|}
\hline & \multicolumn{5}{|c|}{ Liquid/solid $=5$} & \multicolumn{5}{|c|}{ Liquid $/$ solid $=10$} \\
\hline & $3 \mathrm{~h}$ & $5 \mathrm{~h}$ & $10 \mathrm{~h}$ & $40 \mathrm{~h}$ & $70 \mathrm{~h}$ & $3 \mathrm{~h}$ & $5 \mathrm{~h}$ & $10 \mathrm{~h}$ & $40 \mathrm{~h}$ & $70 \mathrm{~h}$ \\
\hline Final $\mathrm{pH}$ & 1.36 & 2.63 & 3.41 & 6.24 & 6.48 & 0.92 & 1.32 & 2.41 & 5.96 & 6.13 \\
\hline $\mathrm{Na}$ & 30.1 & 62.1 & 53.0 & 49.8 & 47.7 & 55.4 & 102 & 66.1 & 68.1 & 96.3 \\
\hline $\mathrm{Mg}$ & 36.6 & 50.0 & 27.7 & 20.2 & 10.2 & 75.8 & 103 & 103 & 107 & 105 \\
\hline $\mathrm{Al}$ & 20.2 & 28.9 & 4.59 & 0.34 & 0.10 & 50.3 & 74.6 & 32.8 & 25.2 & 9.81 \\
\hline $\mathrm{K}$ & 30.8 & 56.8 & 45.0 & 48.7 & 69.7 & 49.3 & 89.2 & 57.8 & 55.1 & 69.6 \\
\hline $\mathrm{Ca}$ & 61.6 & 77.7 & 81.6 & 87.7 & 86.6 & 69.8 & 98.9 & 101 & 100 & 102 \\
\hline $\mathrm{Ti}$ & 0.56 & 6.85 & 2.25 & 1.28 & 1.34 & 2.89 & 65.8 & 19.0 & 6.61 & 6.54 \\
\hline $\mathrm{V}$ & 2.21 & 13.1 & 8.25 & 6.35 & 5.98 & 26.4 & 76.8 & 29.2 & 28.6 & 54.9 \\
\hline $\mathrm{Cr}$ & 12.0 & 13.6 & 11.5 & 12.6 & 12.8 & 21.4 & 27.3 & 28.7 & 27.8 & 22.4 \\
\hline $\mathrm{Mn}$ & 24.9 & 35.6 & 18.9 & 9.82 & 5.99 & 72.2 & 91.4 & 80.4 & 106 & 103 \\
\hline $\mathrm{Fe}$ & 14.0 & 10.1 & 7.16 & 0.13 & 0.21 & 35.2 & 62.9 & 63.7 & 60.5 & 65.7 \\
\hline Co & 1.35 & 13.0 & 4.21 & 3.18 & 1.24 & 60.6 & 85.7 & 48.2 & 36.4 & 62.0 \\
\hline $\mathrm{Ni}$ & 17.5 & 18.2 & 5.66 & 2.49 & 0.04 & 41.0 & 105 & 104 & 104 & 105 \\
\hline $\mathrm{Cu}$ & 37.4 & 25.8 & 10.4 & 6.86 & 0.49 & 42.6 & 51.0 & 24.2 & 3.38 & 5.93 \\
\hline $\mathrm{Zn}$ & 37.2 & 47.8 & 25.6 & 11.5 & 2.04 & 71.8 & 109 & 67.4 & 86.6 & 20.8 \\
\hline As & 28.3 & 36.5 & 29.1 & 18.8 & 9.06 & 39.6 & 88.1 & 63.9 & 32.0 & 58.3 \\
\hline $\mathrm{Sr}$ & 40.5 & 89.6 & 52.0 & 57.6 & 69.4 & 76.0 & 102 & 82.5 & 58.2 & 32.5 \\
\hline $\mathrm{Cd}$ & 102 & 99.8 & 79.2 & 75.3 & 73.0 & 102 & 105 & 103 & 103 & 102 \\
\hline $\mathrm{Ba}$ & 6.59 & 10.5 & 4.54 & 41.9 & 45.6 & 7.57 & 88.6 & 70.1 & 76.1 & 79.9 \\
\hline $\mathrm{Pb}$ & 40.5 & 58.6 & 14.0 & 8.95 & 2.00 & 47.0 & 96.5 & 33.8 & 10.1 & 7.36 \\
\hline
\end{tabular}

Hydrothermal temperature $=150^{\circ} \mathrm{C}$.

indicating that the acid was rapidly consumed by $\mathrm{Ca}$. However, under hydrothermal condition, the solution $\mathrm{pH}$ changed very slowly, e.g. changed to around 1 within $1 \mathrm{~h}$ and around 2.5 within $5 \mathrm{~h}$. The acid was almost completely consumed after $40 \mathrm{~h}$ hydrothermal treatment.

\subsection{Effect of hydrothermal treatment time on metal extraction}

The effect of hydrothermal treatment time on metal extraction from the ash was examined at liquid/solid ratios of 5:1 and 10:1 (ml:g). Table 3 shows that almost the same trends for the two ratios were found. The maximum metal extraction percentages were obtained at $5 \mathrm{~h}$, and further hydrothermal treatment conversely reduced the extraction effect. For example, at a liquid/solid ratio of 5:1 (ml:g), 99.8\% $\mathrm{Cd}$ and $58.6 \% \mathrm{~Pb}$ could be extracted into the leachate at a period of $5 \mathrm{~h}$ hydrothermal treatment, but the extraction percentages reduced to $73 \%$ and $2 \%$ respectively after $40 \mathrm{~h}$ treatment. Under hydrothermal condition, the behaviors of metallic elements in the ash follow the two ways, i.e. hydrothermal leaching firstly and then hydrothermal precipitation along with the treatment time. This viewpoint is strongly supported by the XRD patterns and SEM photographs of the ash obtained at different hydrothermal treatment times. Fig. 2 depicts that many of the crystalline components were destroyed after $5 \mathrm{~h}$ hydrothermal treatment, indicating that metallic elements were leached out from the ash into the leachate. However, many new peaks appeared after $40 \mathrm{~h}$ hydrothermal treatment. These peaks are mainly the crystalline peaks of $\mathrm{SiS}_{2}$ and $\mathrm{CaSO}_{4}$. It is of concern how the $\mathrm{SiS}_{2}$ crystal was formed under the condition of the present study. The ash used in this study typically contains about $4 \% \mathrm{Si}$ and $1 \% \mathrm{~S}$, part of both elements might be firstly leached out in the hydrochloric acid solution and gradually crystallized along with the hydrothermal treatment. The $d$-space values for the $\mathrm{SiS}_{2}$ crystal were about 2.22-3.59 $\AA$ calculated by Bragg's equation $(n \lambda=2 d \sin \theta)$. These data reflect the average intersegmental distance of the $\mathrm{SiS}_{2}$ crystals. SEM images (Fig. 5) of the ashes under various treatments indicate that metal leaching mechanisms are quite different under these conditions.

Table 4

Element extraction percentages by $1 \mathrm{M} \mathrm{HCl}$ solution at different hydrothermal treatment temperatures $(\%)$

\begin{tabular}{lccccc}
\hline & $100{ }^{\circ} \mathrm{C}$ & $120^{\circ} \mathrm{C}$ & $150{ }^{\circ} \mathrm{C}$ & $180{ }^{\circ} \mathrm{C}$ & $200^{\circ} \mathrm{C}$ \\
\hline $\mathrm{Final} \mathrm{pH}$ & 1.57 & 1.26 & 2.63 & 1.74 & 1.71 \\
$\mathrm{Na}$ & 31.2 & 31.3 & 62.1 & 40.8 & 8.31 \\
$\mathrm{Mg}$ & 35.5 & 34.9 & 50.0 & 33.1 & 25.6 \\
$\mathrm{Al}$ & 18.9 & 20.2 & 28.9 & 15.0 & 0.19 \\
$\mathrm{~K}$ & 32.2 & 33.2 & 56.8 & 42.9 & 47.6 \\
$\mathrm{Ca}$ & 59.8 & 55.3 & 77.7 & 57.6 & 65.7 \\
$\mathrm{Ti}$ & 0.36 & 0.58 & 6.80 & 0.28 & 0.11 \\
$\mathrm{~V}$ & 29.5 & 31.0 & 13.1 & 19.5 & 1.65 \\
$\mathrm{Cr}$ & 6.65 & 6.85 & 13.6 & 3.67 & 0.65 \\
$\mathrm{Mn}$ & 23.9 & 24.9 & 35.6 & 25.2 & 20.7 \\
$\mathrm{Fe}$ & 12.2 & 13.0 & 10.1 & 11.7 & 4.65 \\
$\mathrm{Co}$ & 11.2 & 9.29 & 13.0 & 9.26 & 5.55 \\
$\mathrm{Ni}$ & 22.4 & 24.8 & 18.2 & 15.6 & 14.5 \\
$\mathrm{Cu}$ & 27.8 & 27.6 & 25.8 & 18.9 & 3.58 \\
$\mathrm{Zn}$ & 37.1 & 35.6 & 47.8 & 31.8 & 24.6 \\
$\mathrm{As}$ & 36.9 & 38.9 & 36.5 & 67.2 & 17.1 \\
$\mathrm{Sr}$ & 45.3 & 43.8 & 89.6 & 48.8 & 55.1 \\
$\mathrm{Cd}$ & 94.9 & 97.9 & 99.8 & 89.4 & 62.0 \\
$\mathrm{Ba}$ & 2.50 & 2.88 & 10.5 & 4.04 & 5.59 \\
$\mathrm{~Pb}$ & 30.8 & 31.5 & 58.6 & 23.0 & 2.06 \\
\hline & & & & &
\end{tabular}

Liquid $/$ solid $=5 \mathrm{ml} / \mathrm{g}$, treatment time $=5 \mathrm{~h}$. 

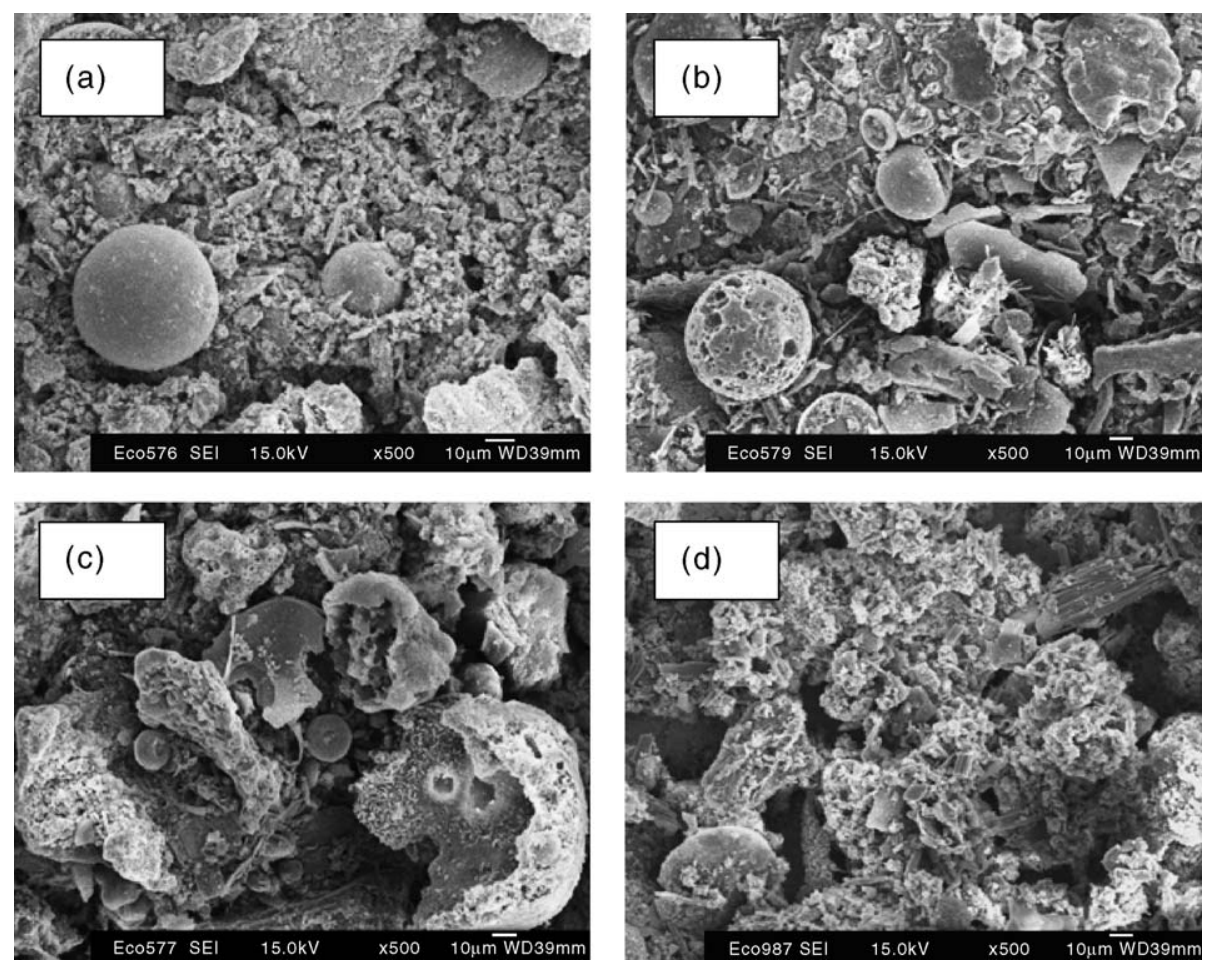

Fig. 5. SEM images of (a) pre-treated fly ash, (b) $1 \mathrm{M} \mathrm{HCl}$ treated fly ash at room condition, (c) hydrothermal treated fly ash by $1 \mathrm{M} \mathrm{HCl}$ for $5 \mathrm{~h}$, (d) hydrothermal treated fly ash by $1 \mathrm{M} \mathrm{HCl}$ for $40 \mathrm{~h}$. Room conditions: temperature $=20^{\circ} \mathrm{C}$, liquid/solid $=10$, contact time $=5 \mathrm{~h}$; hydrothermal conditions: temperature $150{ }^{\circ} \mathrm{C}$, liquid/solid $=10$.

At room temperature, the leaching is a surface controlled process (Fig. 5b), but under hydrothermal condition, the subcritical acidic solution could diffuse into the ash particles thus split them into fragments (Fig. 5c). This process could greatly accelerate the leaching effect of metals inside the particle into the liquor. Furthermore, the crystals such as $\mathrm{SiS}_{2}$ and $\mathrm{CaSO}_{4}$ after long time hydrothermal treatment were also confirmed in SEM image (Fig. 5d).

Table 5

Effect of liquid/solid ratio on element leaching by $1 \mathrm{M} \mathrm{HCl}$ solution under hydrothermal treatment

\begin{tabular}{|c|c|c|c|c|c|c|c|c|}
\hline & \multicolumn{8}{|c|}{ Liquid/solid ratio } \\
\hline & \multicolumn{2}{|l|}{$3: 1$} & \multicolumn{2}{|l|}{$5: 1$} & \multicolumn{2}{|l|}{$10: 1$} & \multicolumn{2}{|l|}{$20: 1$} \\
\hline & $m g 1^{-1}$ & $\%$ & $m g 1^{-1}$ & $\%$ & $\mathrm{mg}^{-1}$ & $\%$ & $\mathrm{mg} 1^{-1}$ & $\%$ \\
\hline Final pH & 6.77 & & 2.63 & & 1.32 & & 0.52 & \\
\hline $\mathrm{Na}$ & 1484 & 45.6 & 1204 & 62.1 & 1004 & 102 & 520 & 99.8 \\
\hline $\mathrm{Mg}$ & 603 & 16.5 & 1085 & 50.0 & 1136 & 103 & 592 & 101 \\
\hline $\mathrm{Al}$ & 275 & 2.90 & 1637 & 28.9 & 2142 & 74.6 & 1592 & 105 \\
\hline $\mathrm{K}$ & 1507 & 45.4 & 1121 & 56.8 & 894 & 89.2 & 544 & 103 \\
\hline $\mathrm{Ca}$ & 13720 & 32.8 & 19376 & 77.7 & 12516 & 98.9 & 6844 & 102 \\
\hline $\mathrm{Ti}$ & 18.9 & 1.18 & 65.2 & 6.82 & 319 & 65.8 & 230 & 89.5 \\
\hline $\mathrm{V}$ & 0.32 & 9.51 & 0.26 & 13.1 & 0.78 & 76.8 & 0.53 & 98.6 \\
\hline $\mathrm{Cr}$ & 1.73 & 2.90 & 4.85 & 13.6 & 4.94 & 27.3 & 7.11 & 74.2 \\
\hline $\mathrm{Mn}$ & 12.1 & 3.75 & 68.8 & 35.6 & 89.7 & 91.4 & 54.7 & 105 \\
\hline $\mathrm{Fe}$ & 164 & 6.40 & 155 & 10.1 & 487 & 62.9 & 425 & 104 \\
\hline $\mathrm{Co}$ & 0.03 & 0.46 & 0.42 & 13.0 & 1.42 & 85.7 & 0.87 & 99.5 \\
\hline $\mathrm{Ni}$ & 0.10 & 0.78 & 1.34 & 18.2 & 3.89 & 104 & 2.01 & 101 \\
\hline $\mathrm{Cu}$ & 0.93 & 0.31 & 46.4 & 25.8 & 46.5 & 51.0 & 49.6 & 103 \\
\hline $\mathrm{Zn}$ & 164 & 2.86 & 1636 & 47.8 & 1894 & 109 & 906 & 98.5 \\
\hline As & 0.91 & 12.6 & 1.57 & 36.5 & 1.93 & 88.1 & 1.12 & 96.7 \\
\hline $\mathrm{Sr}$ & 34.5 & 52.3 & 35.2 & 89.6 & 20.1 & 101 & 10.5 & 99.7 \\
\hline $\mathrm{Cd}$ & 37.0 & 78.6 & 28.0 & 99.8 & 14.9 & 105 & 7.88 & 105 \\
\hline $\mathrm{Ba}$ & 3.19 & 24.3 & 0.82 & 10.5 & 3.51 & 88.6 & 2.03 & 96.8 \\
\hline $\mathrm{Pb}$ & 12.8 & 4.03 & 111 & 58.6 & 92.7 & 96.5 & 52.7 & 104 \\
\hline
\end{tabular}

Temperature $=150^{\circ} \mathrm{C}$, treatment time $=5 \mathrm{~h}$. 


\subsection{Effects of hydrothermal temperature and liquid/solid ratio on metal extraction}

The ionization state of hydrochloric acid under hydrothermal condition relates closely to temperature, hence the leaching speed of metals from the ash was greatly affected by the hydrothermal temperatures. Table 4 indicates that the optimum hydrothermal treatment temperature is $150{ }^{\circ} \mathrm{C}$. At lower temperature, the ash particles could not split, and conversely, at higher temperature, the acid is not effectively ionized, both of which restrict the chemical reactions of metal extraction. Metal extraction from ash sample under hydrothermal condition is a complicated process, including competition among dissolution, neo-formation and precipitation.

The effect of liquid/solid ratio on metal leaching efficiency was examined with the ratios change from $3: 1$ to $20: 1(\mathrm{ml}: \mathrm{g})$ (Table 5). At lower liquid/solid ratio, such as 3:1 and 5:1 (ml:g), only limited amount of metals was leached out. Over addition of hydrochloric acid into the reaction system could sufficiently extract metals from the ash, but the resulting residue and the leachate were extremely acidic, requiring high-level wastewater and residue control, e.g. the $\mathrm{pHs}$ of the leachates at liquid/solid ratios of 10:1 and 20:1 (ml:g) were 1.32 and 0.52 , respectively. For liquid/solid ratio of 5:1 (ml:g), the final $\mathrm{pH}$ of the leachate was 2.63, indicating that there was enough acid available, but low metal leaching ratios were still obtained since the reaction solution was close to saturation due to the lack of liquid. According to the results in Table 5, a suitable liquid/solid ratio of 10:1 $(\mathrm{ml}: \mathrm{g})$ is recommended. In this case, most of the major metals, such as $\mathrm{Na} \mathrm{Mg}, \mathrm{Al}, \mathrm{K}, \mathrm{Ca}$ are leached out, and the leaching percentages for environmental concern metals, such as $\mathrm{Cd}$ and $\mathrm{Pb}$, are $100 \%$ and $97 \%$, respectively.

It can be seen from Table 5 that $\mathrm{Cr}$ was difficult to be extracted, e.g. only $27 \%$ and $74 \%$ of $\mathrm{Cr}$ were leached out at liquid/solid ratios of 10:1 and 20:1 (ml:g), respectively. The effective extraction method of $\mathrm{Cr}$ from the ash will be a new theme for future study.

\section{Conclusions}

An effective process for metal extraction from MSW incinerator fly ash was established in the present work. The process consists of two steps, i.e. pre-washing and hydrothermal extraction. Pre-washing could extract $67 \% \mathrm{Na}, 76 \% \mathrm{~K}, 48 \% \mathrm{Ca}, 5 \% \mathrm{~Pb}$ and $1 \% \mathrm{Zn}$ from the ash, respectively. The optimum pre-washing time is $30 \mathrm{~min}$. Longer time washing will reduce the extraction effect for some of the hazardous heavy metals. XRD patterns indicate that some of the $\mathrm{Na}$ and $\mathrm{K}$ in the ash are in the forms of crystalline of $\mathrm{NaCl}$ and $\mathrm{KCl}$, but $\mathrm{Ca}$ exists in its amorphous form.

Hydrochloric acid is the most effective extraction reagent among the five types of tested acids. Under hydrothermal condition, hydrochloric acid simultaneously reacts with all the metals in the ash, but the acid preferentially reacts with $\mathrm{Ca}$ under room condition. SEM images indicate that hydrothermal treatment could split the ash particles into fragments hence promotes the reaction of the acid with hazardous metals such as $\mathrm{Cr}$,
$\mathrm{Cd}, \mathrm{Pb}$, and furthermore, slows down the consumption of the acid.

The maximum metal extraction percentages were obtained at $5 \mathrm{~h}$, and longer hydrothermal treatment conversely reduced the extraction effect. Therefore, it is suggested that the behaviors of metallic elements in the ash follow the two ways under hydrothermal condition, i.e. hydrothermal leaching and hydrothermal precipitation. This viewpoint was supported by the formation of crystals such as $\mathrm{SiS}_{2}$ and $\mathrm{CaSO}_{4}$ after $40 \mathrm{~h}$ hydrothermal treatment. The optimum hydrothermal treatment temperature and liquid/solid ratio were found to be $150{ }^{\circ} \mathrm{C}$ and 10:1 (ml:g), respectively. After hydrothermal treatment at optimum conditions, the residue mainly contains $\mathrm{Si}, \mathrm{S}, \mathrm{C}, \mathrm{P}$ and $\mathrm{O}$ with a little amount of $\mathrm{Cr}$, thus has the potential to be used for silicon and sulfur fertilizer manufacture after further removal of $\mathrm{Cr}$.

\section{Acknowledgments}

This work was made possible by the financial support from the Japan Society for the Promotion of Science and the Chinese Academy of Sciences. The authors gratefully acknowledge K. Kato for his kindly cooperation in sample collection.

\section{References}

[1] Jap Waste Res Foundation, A Hand Book for Special Controlled Wastes Treatment, Chemical Nippo, 1993, pp. 31-32.

[2] F. Andreola, L. Barbieri, A. Corradi, I. Lancellotti, T. Manfredini, Utilisation of municipal incinerator grate slag for manufacturing porcelainized stoneware tiles manufacturing, J. Eur. Ceram. Soc. 22 (2002) 1457-1462.

[3] S. Sakai, M. Hiraoka, Municipal solid waste incinerator residue recycling by thermal processes, Waste Manage. 20 (2000) 249-258.

[4] M. Andac, F.P. Glasser, The effect of test conditions on the leaching of stabilized MSWI-fly ash in portland cement, Waste Manage. 18 (1998) 309-316.

[5] A. Mizutani, T. Yoshida, S. Sakai, H. Takatsuki, Release of metals from MSWI fly ash and availability in alkali condition, Waste Manage. 16 (1996) 537-544.

[6] T. Kinoshita, K. Yamaguchi, S. Akita, S. Nii, F. Kawaizumi, K. Takahashi, Hydrometallurgical recovery of zinc from ashes of automobile tire wastes, Chemosphere 59 (2005) 1105-1111.

[7] S. Nagib, K. Inoue, Recovery of lead and zinc from fly ash generated from municipal incineration plants by means of acid and/or alkaline leaching, Hydrometallurgy 56 (2000) 269-292.

[8] H. Katsuure, T. Inoue, M. Hiraoka, S. Sakai, Full-scale plant study on fly ash treatment by the acid extraction process, Waste Manage. 16 (1996) 491-499.

[9] X. Querol, N. Moreno, J. Umana, A. Alastuey, E. Hernandez, A. Lopezsoler, F. Plana, Synthesis of zeolites from coal fly ash: an overview, Intern. J. Coal Geol. 50 (2002) 413-423.

[10] A. Singer, V. Berkgau, Cation exchange properties of hydrothermally treated coal fly ash, Environ. Sci. Technol. 29 (1995) 17481753.

[11] G. Yang, T. Yang, Synthesis of zeolites from municipal incinerator fly ash, J. Hazard. Mater. 62 (1998) 75-89.

[12] S. Goni, A. Guerrero, M.P. Luxan, A. Macias, Activation of the fly ash pozzolanic reaction by hydrothermal conditions, Cem. Concr. Res. 33 (2003) 1399-1405.

[13] W. Ma, P. Brown, Hydrothermal synthesis of tobemorite from fly ashes, Adv. Ceram. Res. 9 (1997) 9-16. 
[14] H. Yamaguchi, E. Shibuya, Y. Kanamura, K. Uyama, M. Nishioka, N. Yamasaki, Hydrothermal decomposition of PCDDs/PCDFs in MSWI fly ash, Chemosphere 32 (1996) 203-208.

[15] S. Hashimoto, K. Watanabe, K. Nose, M. Morita, Remediation of soil contaminated with dioxins by subcritical water extraction, Chemosphere 54 (2004) 89-96.

[16] R. Mambote, M. Reuter, P. Krijgsman, R. Schuiling, Hydrothermal metallurgy: an overview of basic concepts and applications, Miner. Eng. 13 (2000) 803-822.
[17] F.S. Zhang, H. Itoh, Adsorbents made from waste ashes and postconsumer PET and their potential utilization in wastewater treatment, J. Hazard. Mater. B 101 (2003) 323-337.

[18] F.S. Zhang, H. Itoh, Iron-oxide loaded slag for arsenic removal from aqueous system, Chemosphere (2005) 319-325.

[19] P.A. Marrone, P.M. Gschwend, K.C. Swallow, W.A. Peters, J.W. Tester, Product distribution and reaction pathways for methylene chloride hydrolysis and oxidation under hydrothermal conditions, J. Hydrocrit. Fluids (1998) 239-254. 